\title{
INFORMATION TECHNOLOGY AND GENDER EQUALITY: A CONTRADICTION IN TERMINIS?†
}

\author{
INGEBORG JANSSEN REINEN and TJEERD PLOMP \\ Center for Applied Educational Research, Faculty of Educational Science and Technology, University of \\ Twente, P.O. Bux 217, 7500 AE Enschede, The Netherlands \\ [Fax: +3153489 3023; e-mail: janssen_reinen@edte.utwente.nl, plomp@edte.utwente.nl]
}

(Received 25 November 1996; accepted 4 February 1997)

\begin{abstract}
Using the data source of the Computers in Education (Comped) study, carried out under the auspices of the International Association for the Evaluation of Educational Achievement (IEA), the status of gender and computer use in education in a number of countries has been investigated. The findings in this study indicate that the concern about gender cquity expressed by many educational practitioners are right. Females know less about information technology, enjoy using the computer less than male students, and perceive more problems with software. Possible causes of this are differences in parental support, access to computers, amount of female role models and activities carried out with computers in school. Gender differences are being found both outside and inside schools. This means that both teachers and parents have to be made aware of this as a starting point for proper action. Schools rarely have a policy concerning gender issues; and when it exists, it is not directed to parents as well. The U.S.A. is the most "gender equal" country of the countries examined. (C) 1997 Elsevier Science Ltd.
\end{abstract}

\section{INTRODUCTION}

Using the rich data source of the Computers in Education project (Comped), carried out under the auspices of the International Association for the Evaluation of Educational Achievement (IEA), the purpose of this article is to study the status of gender and computer use in education in a number of countries. Is this innovation in education widening the knowledge and skills gap between female and male students, or does the computer provide a means to close this gap? And in case inequity in the area of educational computer use is existing, what are the possible causes of this inequity. and what might be done in the near future to improve the situation?

\section{PERSPECTIVES AND CONCEPTUAL FRAMEWORK}

Much research has been done on the effects of computer use on female as well as male students and it is found in a number of research projects that the daily practice concerning the use of computers in education by female and male students does not reflect the principle of equality [1-4]. Janssen Reinen and Plomp [5] give a summary of the factors found in research on equity and computers. Using Sutton's [6] framework, the following categories of factors have been found to reflect the difference between female and male students:

\section{Input: access and socialization}

From the point of view of education, input variables consist of school external factors that might be of influence on gender differences like access to computers (at home) and different socialization experiences. The student brings these factors with him as input for the school career.

\section{Process: equity issues in school}

In the educational context, all school internal factors that might have an influence on gender differences, are taken into account. Factors found to influence gender inequality are:

- female role models in the class (or the number of female teachers working with the computer in the school and the type of role model they furnish);

- organizational issues (like schools being co-educational or not, or timetabling of school subjects);

$\dagger$ An earlier version of this paper has been presented at the annual meeting of the American Educational Research Association, 2-7 April 1994, New Orleans. 
- type of computer use in school (with gender differences mainly appearing in programming courses and voluntary activities).

\section{Output: student attitudes and ability}

As a result of the home and school situation with regard to computers, research claims that gender differences appear in attitudes towards computers, knowledge about computers and skills to work with computers $[2,3,7-9]$.

The above framework for mapping out gender differences is used to analyse the Comped data. First, a look at the output variables shows whether gender differences are found in the Comped study with regard to knowledge about computers and attitudes towards computers. Factors mentioned in the framework as input or process variables are studied as possible sources of gender differences in knowledge and attitudes.

\section{DATA SOURCE}

The data used for this article are collected in IEA's Comped study, an international comparative survey of computers in education (see [10] for more details about the design of the study). In about 20 different countries in 1989 [11] and in 10 countries in 1992 [10], data were collected on the use of computers in elementary, lower and upper secondary education. In each country, a national representative sample was drawn from computer using and non using schools. Questionnaires were given to principals of schools, computer coordinators and teachers (both computer using teachers as well as teachers who do not work with them). In 1992 data were also collected from students, via a functional information technology test (FITT), an attitude questionnaire and a background questionnaire.

Data from this project allow us to study the students' gender perspective from different angles: the degree of computer use in the schools, the problems experienced, the attitudes towards computers and the way students look at this new technology. Many influencing factors as found in earlier research and theory to be of relevance for the gender debate were taken into account when studying the Comped data.

Table 1 shows the distribution of females and males in the samples of students in the target grades of the study. Only in India in upper secondary education, the percentage of female students is considerably lower than the percentage of male students, while the situation is reversed in Bulgaria in upper secondary education. Furthermore, the distribution is rather equal.

Table 1. Total number of tested students (No.) in the sample of the target grade* and percentage girls $(\% \mathrm{~g})$

\begin{tabular}{|c|c|c|c|c|c|c|}
\hline & \multicolumn{2}{|c|}{$\begin{array}{l}\text { Elementary } \\
\text { Schools }\end{array}$} & \multicolumn{2}{|c|}{$\begin{array}{l}\text { Lower } \\
\text { Secondary } \\
\text { Schools }\end{array}$} & \multicolumn{2}{|c|}{$\begin{array}{l}\text { Upper } \\
\text { Secondary } \\
\text { Schools }\end{array}$} \\
\hline & No. & $\% \mathrm{~g}$ & No. & $\% \mathrm{~g}$ & No. & $\% g$ \\
\hline AUT & - & - & 5397 & 49 & 2797 & 48 \\
\hline BUL & - & - & 2086 & 55 & 2067 & 65 \\
\hline GER & - & - & 1463 & 49 & - & - \\
\hline GRE & - & - & 3635 & 52 & - & - \\
\hline IND & - & - & - & - & 12,945 & 32 \\
\hline JPN & 4939 & 48 & 5481 & 48 & 4572 & 43 \\
\hline LAT & - & - & - & - & 2228 & 54 \\
\hline NET & 3615 & 52 & 4905 & 50 & - & - \\
\hline SLO & - & - & - & - & 3431 & 58 \\
\hline USA & 4316 & 51 & 3746 & 51 & 2999 & 53 \\
\hline
\end{tabular}

-Data not collected; *for elementary and lower secondary schools one target grade was defined and only students from this grade are included in this chapter. For upper secondary education, the target grades differ among and within countries.

Abbreviations used: AUT, Austria; BUL, Bulgaria; GER, Germany; GRE, Greece; IND, India; JPN, Japan; LAT Latvia; NET, Netherlands; SLO, Slovenia; USA, United States of America. 


\section{OUTPUT: DIFFERENCES IN KNOWLEDGE, ATTITUDES AND PROBLEMS EXPERIENCED}

\section{Functional Information Technology knowledge}

A so-called Functional Information Technology-Test was given to the students in the national representative samples in the Comped study. This test is designed to measure the knowledge students have concerning general information handling and simple computer skills. We see the results on the FITT as an indication for student achievement in the field of computer use. For details with respect to this test (content, reliability and validity) we refer to Pelgrum and Plomp [12]. Figure 1 gives the score on the test (for secondary education a 27 item test, for elementary education a subset of this test consisting of 17 items), broken down by gender.

Figure 1 shows that, in most countries under study, male students score significantly higher than females. Bulgaria, India and the U.S.A. are the countries in which no significant difference is found. Although the trend of the gender difference in FITT-score in all countries is clear, the picture shown in Fig. 1 might be somewhat overstating the difference. When bringing back the difference in score between males and females to a difference in number of correct answered items on the test, in elementary school and some countries in lower and upper secondary school a difference of not more than one correct answered item is found. The difference in average number of correct items is never larger than 3 items in a test of 27 items. The largest difference is found in upper secondary education.

\section{Attitudes}

Next to the FIT-Test, a background questionnaire was given to the students containing, amongst others, the attitude scales "relevance" and "enjoyment". We refer to Pelgrum and Plomp [12] for details about the content and reliability of the attitude scales.

With respect to the relevance scale, no significant differences are found between male and female students in most countries under study [7]. Only in Austria, the Netherlands and Latvia are male students more convinced of the relevance of learning to work with computers.

When looking at the enjoyment scale, a different picture appears (Fig. 2). In all countries (except Japan and the U.S.A. in elementary education and India in upper secondary education), female students tend to enjoy using the computer significantly much less than males do.

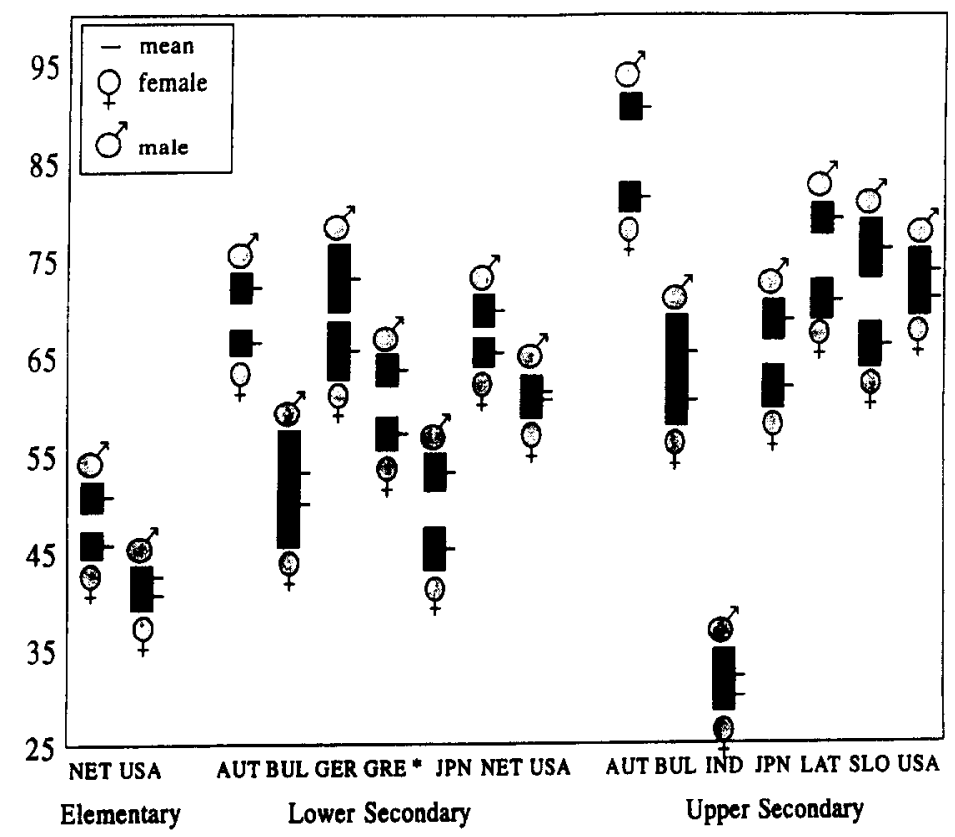

Fig. 1. Mean FITT-score and $95 \%$ confidence interval for female and male students. *Only students in computer using schools. 


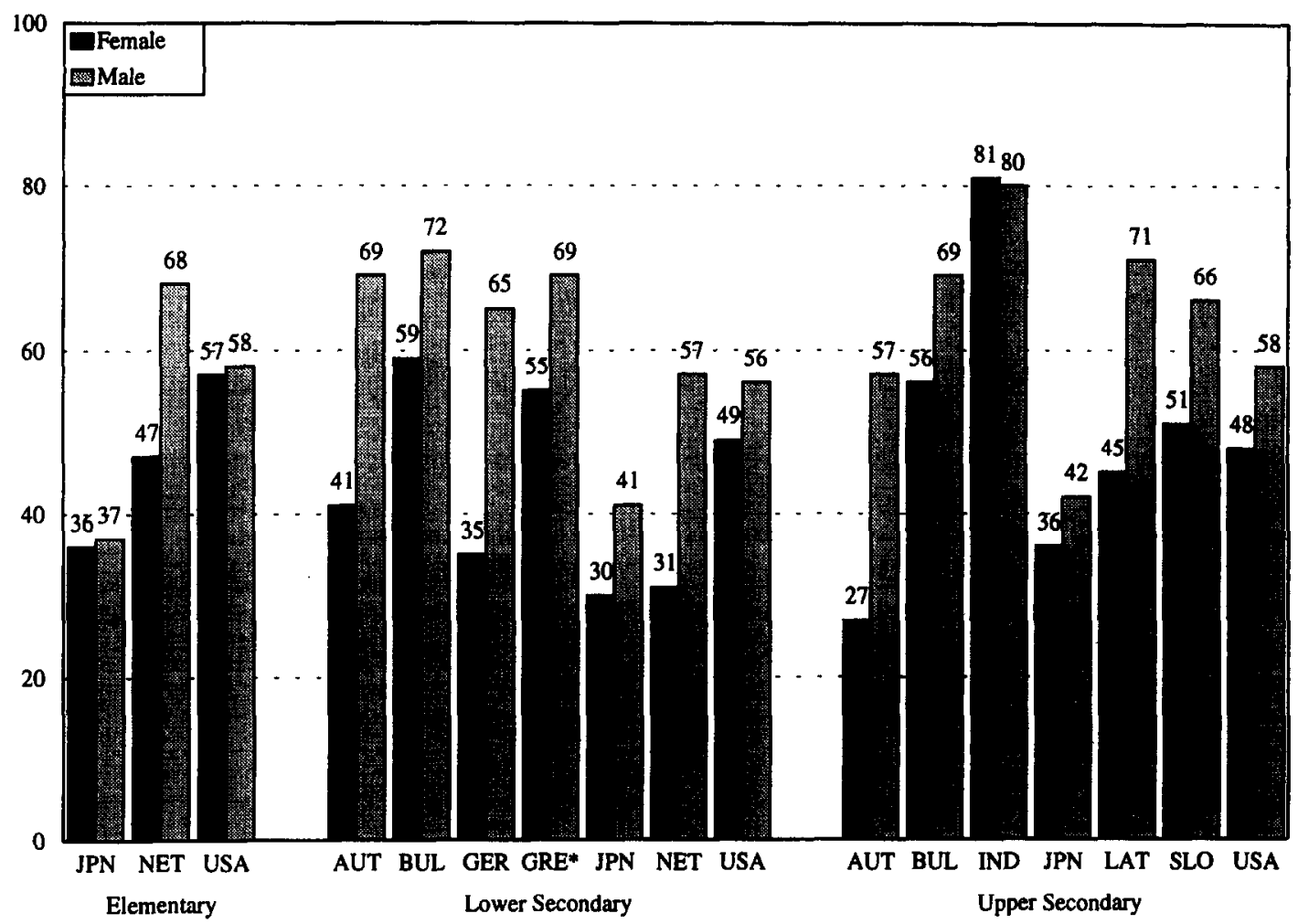

Fig. 2. Percentage (strongly) agree on attitude scale "enjoyment" for both female and male students. $\mathrm{M}=$ information not available or too many missing cases ( $>20 \%)$. ${ }^{*}$ Only students in computer using schools.

\section{Gender specific opinions}

Beside the questions on attitudes, some questions also were stated about the students' opinion on gender issues and computer use; see Table 2. The detailed answers to these questions of both female and male sudents are included in Appendix A.

A majority of students, both female and male, in almost all countries think that both boys and girls equally enjoy using computers for practical jobs. This is not completely in line with the earlier findings on the agreement with the enjoyment scale in the attitude questionnaire, where we found that girls score considerably lower than boys on attitude statements about their own enjoyment. These findings might be explained with the so-called "we can, but I can't" paradox [13]. When explicitly asked about a gender difference (as in the question stated in Table 2), females might feel the need to stress equality between both gender groups in general (we can), but when asked about their own individual attitudes, they personally feel less enjoyment in using computers (I can't).

A comparison can also be made between the question who do you think knows more about computers

Table 2. Questions concerning gender related options

\begin{tabular}{|c|c|c|c|}
\hline Question & & Opinion & \\
\hline Who, do you think, is more likely to play computer games? & Boys & $\begin{array}{c}\text { Equally } \\
\text { Boys and girls }\end{array}$ & Girls \\
\hline Who, do you think, is more likely to enjoy using computers for practical jobs? & Boys & $\begin{array}{l}\text { Equally } \\
\text { Boys and girls }\end{array}$ & Girls \\
\hline Who, do you think, is more likely to get a job doing computer programming? & Boys & $\begin{array}{l}\text { Equally } \\
\text { Boys and girls }\end{array}$ & Girls \\
\hline Who, do you think, knows more about computers? & Boys & $\begin{array}{l}\text { Equally } \\
\text { Boys and girls }\end{array}$ & Girls \\
\hline
\end{tabular}


and the results of the FIT-Test. In Germany, Japan, India and the U.S.A. it can be said that both a majority of female and male students best predict the knowledge of girls and boys when answering the question who is more likely to know more about computers. In Germany and Japan (in all populations) both female and males think that boys know more about computers and this is confirmed with the score on the FIT-Test. Similarly, both females and males in India and the U.S.A. (in all populations) think that boys and girls have an equal amount of knowledge about computers. Again, this is confirmed by the FITT.

\section{Problems}

To investigate what problems students experience when working with computers, the following statements were given to them:

- Computers are not available when I want to use them;

- Programs are difficult to understand and/or use;

- Programs are not to my interest;

- Help is not available when I need it (answer categories: no, never, sometimes, often, very often).

Janssen Reinen and Plomp [7] conclude that no clear overall picture for all countries can be given when looking at the responses of female and male students. The data allow only one conclusion: consistently in secondary education in all countries more female than male students report that they have difficulties in understanding and using programs.

To summarize, when looking at the current situation in educational computer use from the perspective of gender differences, the trends seem to point in the direction of a less positive situation for female students. They score lower on the FIT-Test and their attitudes are less favourable than those of the male students, especially when looking at "enjoyment to work with computers". At best, females think in general that the computer is something for them as well as for males, but personally they do not feel as attracted to computers as male students do. Finally, female students in some countries seem to have more problems with the software (being too difficult or not to their interest). Overall, the most "gender equal" picture on computer use by students is found in Bulgaria and the U.S.A., while Austria, Germany and Latvia seem to be the countries with the largest gender differences in knowledge about, attitudes towards and problems with computers.

\section{INPUT: SOCIALIZATION AND ACCESS AS POSSIBLE CAUSES OF GENDER DIFFERENCES}

As indicated when describing the framework for gender differences, the factors that may influence the difference between female and male students in their knowledge about and attitudes towards computers can be grouped as "input variables" and "process variables". The first category deals with factors "outside" the school environment, while process variables deal with issues in the daily educational practice.

\section{Socialization experience}

Socialization experience is one possible factor of influence on student outcomes in the field of computer use. It refers to the influence of differential socialization of males and females, often resulting in stereotypical sex-specific roles $[3,8]$. These socialization differences can be influenced by the stimulation of parents or through imitation of "significant others". As Yeloushan [14] states, a major social barrier for females is the attitudes of parents and teachers who believe that computers are learning tools predominantly for males.

When looking at the stimulation of parents in the field of computer use, Fig. 3 shows what students think about their parental support. In some countries, the differences between female and male students on their agreement with both parental support items is noteworthy (like the Netherlands, Greece, Latvia and upper sccondary schools in Bulgaria), indicating that males get more support from their parents. Only in Japan, girls agree more with the parental support items.

This result might be an indication of the difference in socialization between girls and boys. However, some caution is necessary in interpreting the data because the way students answered the two opinion 


\section{Parents Encourage Me}

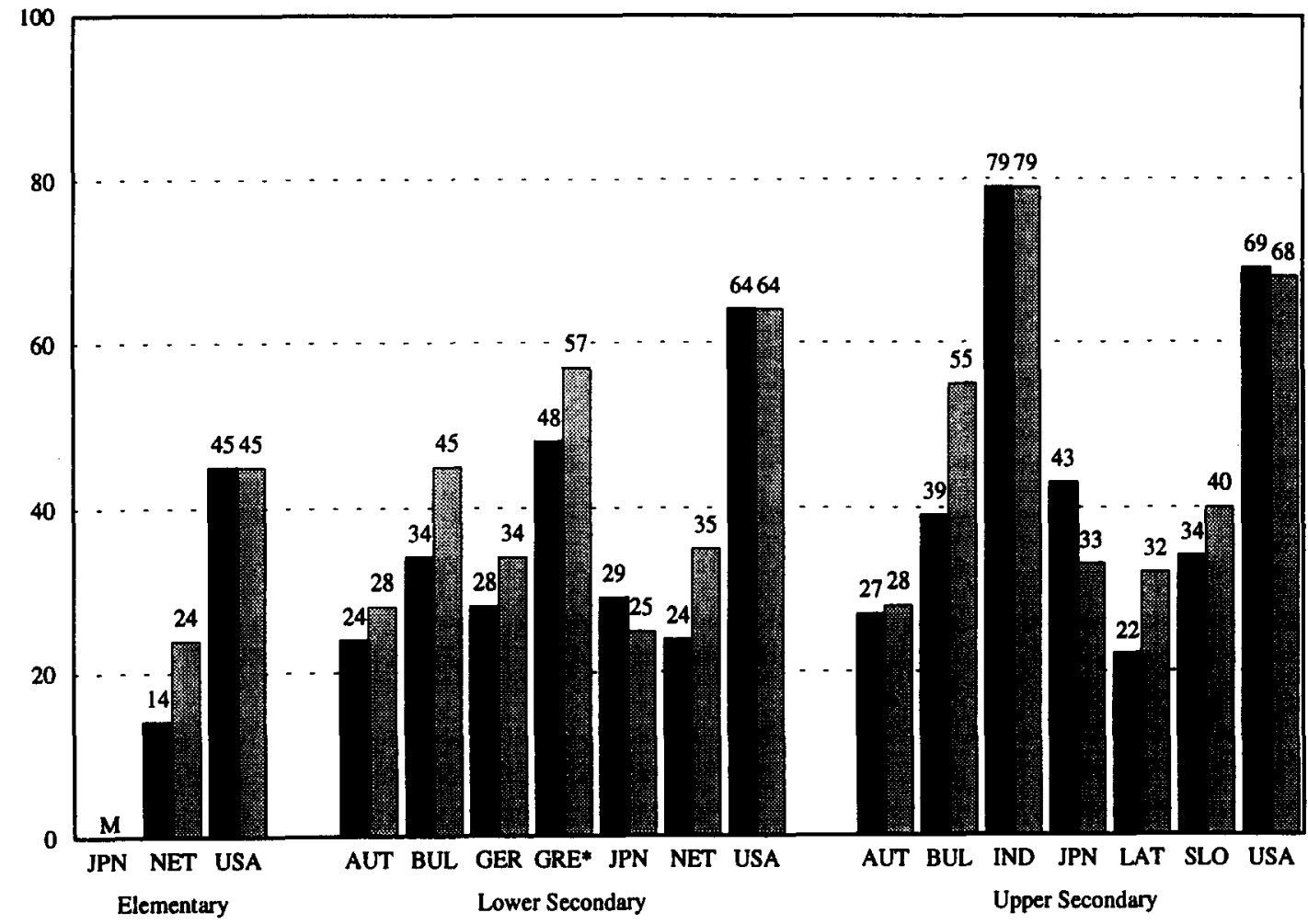

Parents Want Me to be Good

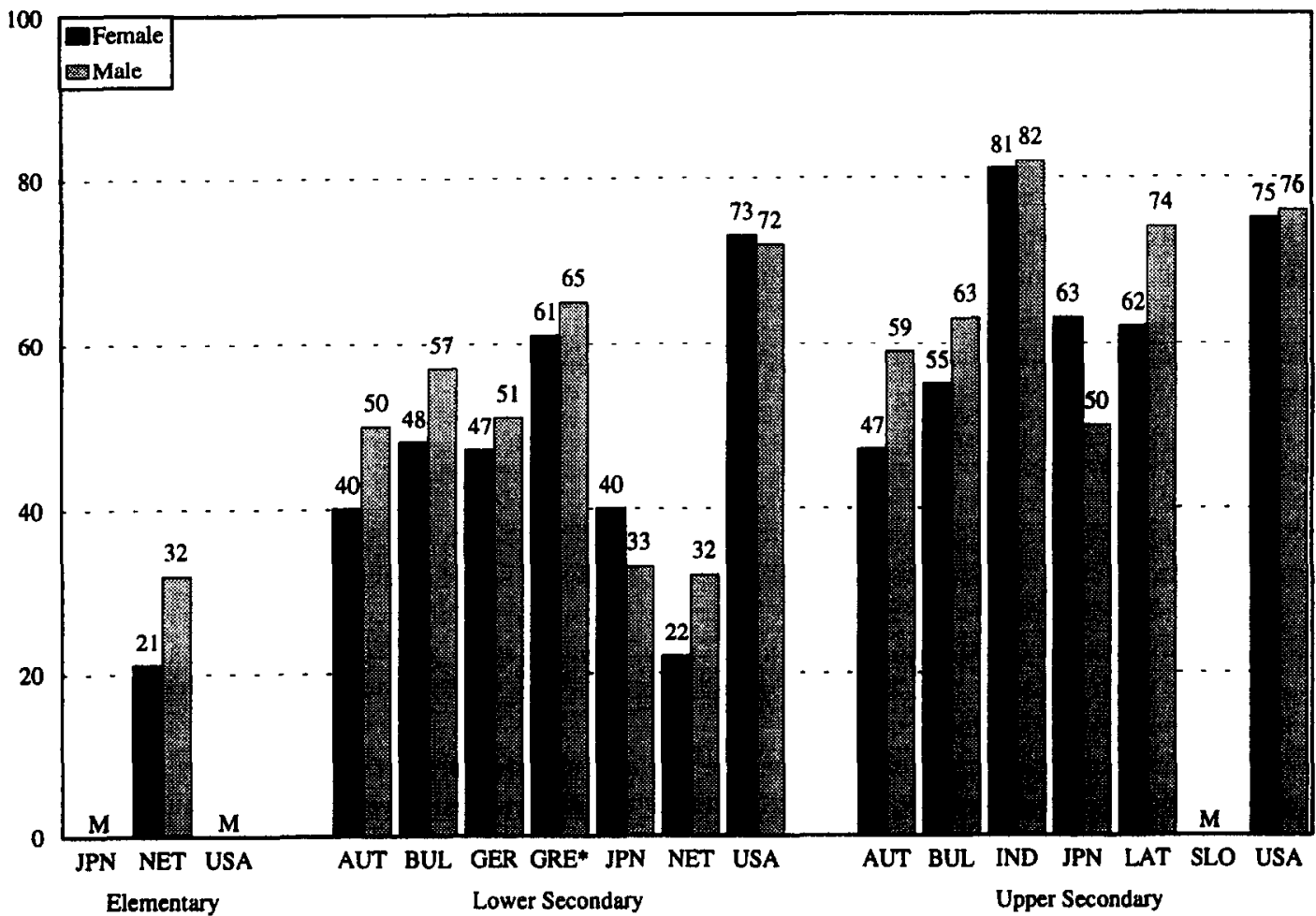

Fig. 3. Percentage (strongly) agree on the parental support attitude items for both female and male students. *Only students in computer using schools. 
items might be influenced by social desirability and, as such, the results might reflect the socialization role that is expected from students and not so much the objective amount of (or lack of) parental support.

\section{Access to computers}

Access to computers at home is another "input indicator" for gender differences. In terms of the availability of computers at home (Fig. 4), it is clear that male students have more possibilitics to work with computers than females do. This difference is significant for all countries but the U.S.A. in elementary and lower secondary education and India in upper secondary education. Japan is not included in the figure because this question was not asked.

This finding is somewhat surprising, as one hypothesis about availability of home computers could be that purchasing of computers would be determined by the enthusiasm of the parents, especially the father in the family, which would imply that as such no gender difference was expected for the availability of computers at home for female and male students.

In addition to looking at access to computers in terms of availability at home, one can also look at the use of computers at school and/or outside school. Four different groups of students can be distinguished, namely "no use at all", "only computer use outside school", "only computer use at school" and "computer use both outside and inside school". Figure 5 shows the percentage of male and female students belonging to each of the four groups.

The female group that has no access to computers is larger than the male group in Austria and Japan in lower and upper secondary school, in Bulgaria in lower secondary and in Latvia in upper secondary education. Inspection of the gender groups that use the computer only at school or in and outside school, shows that in especially Austria, Bulgaria, Germany, Greece and Slovenia female students are predominantly represented in the group that has access to computers only at school. However, some caution must be taken into account when interpreting these findings, as the question about the use of computers at school and/or outside school has been asked for computer use during the year of data

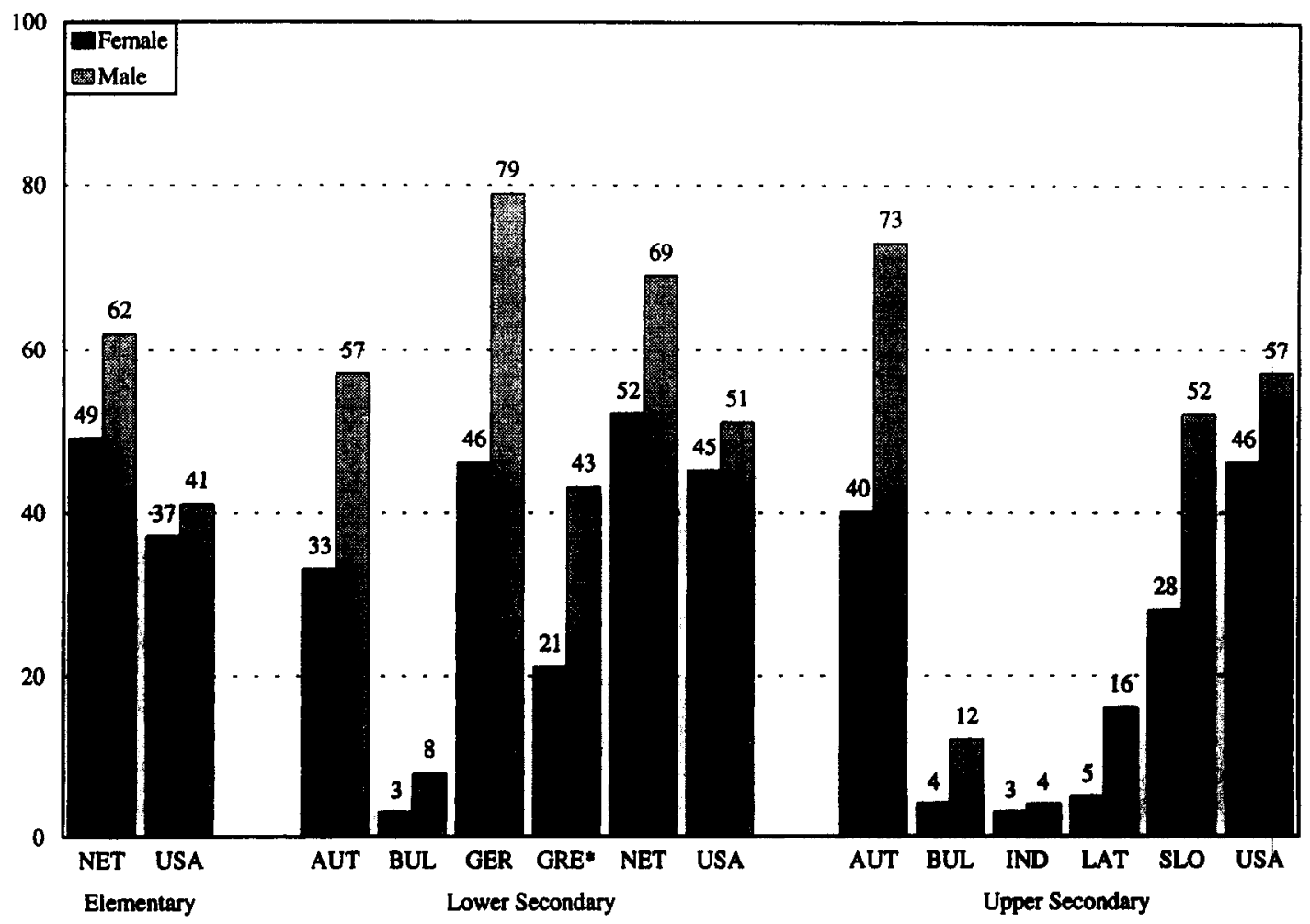

Fig. 4. Percent female and male students indicating having a computer available at home. *Only students in computer using schools. 
collection (1992) only. It is possible that the students have worked with computers at school before the year in which data collection took place.

A first exploration has been done to find out what the influence of access to computers (in terms of using the computer) is on the outcomes at student level.

In all countries, except the Netherlands, the FITT-score of female students using the computer in school is higher than the score for the females only using the computer outside school. This finding seems to be an indication that in these countries school use of the computer is important for female students.

For males, the situation is more diverse. In both lower and upper secondary education, there are two countries in which the boys' score on the FIT-Test is higher when they use the computer only outside

\section{Elementary School}

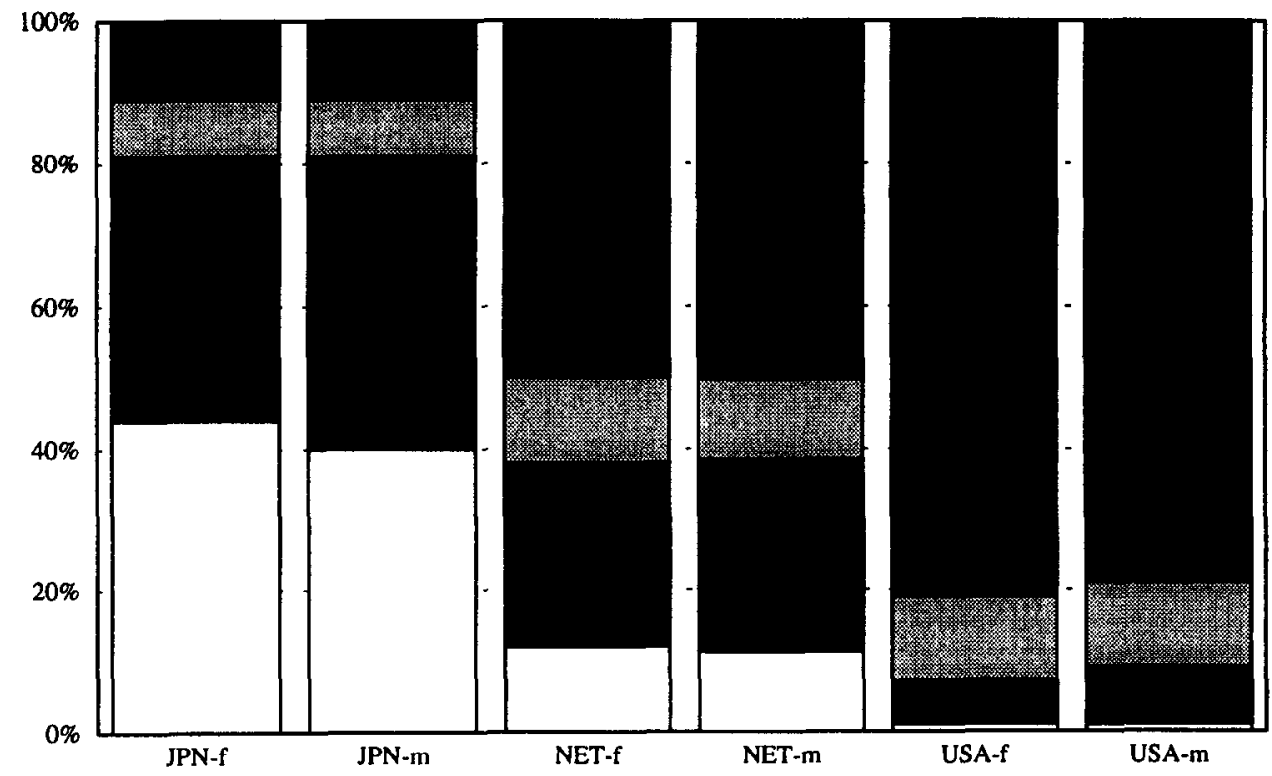

Lower Secondary School

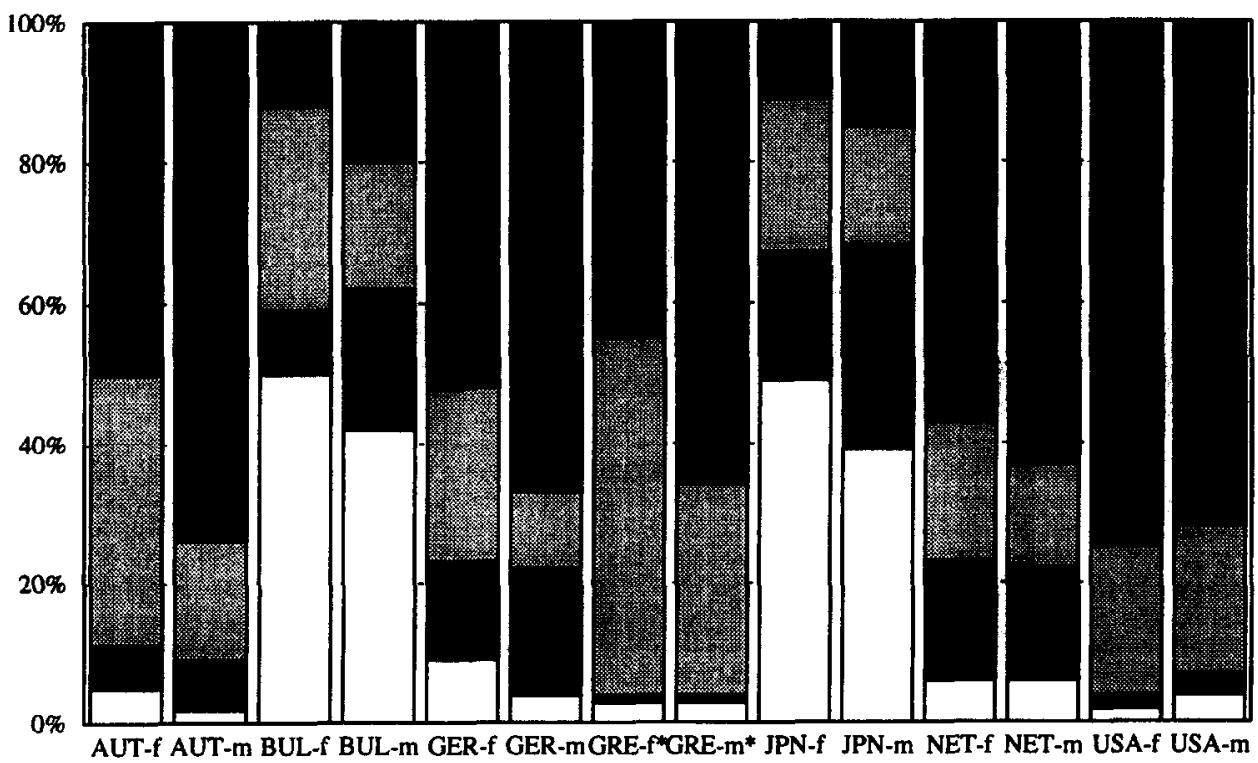

Fig. 5. Continued on facing page. 


\section{Upper Secondary School}

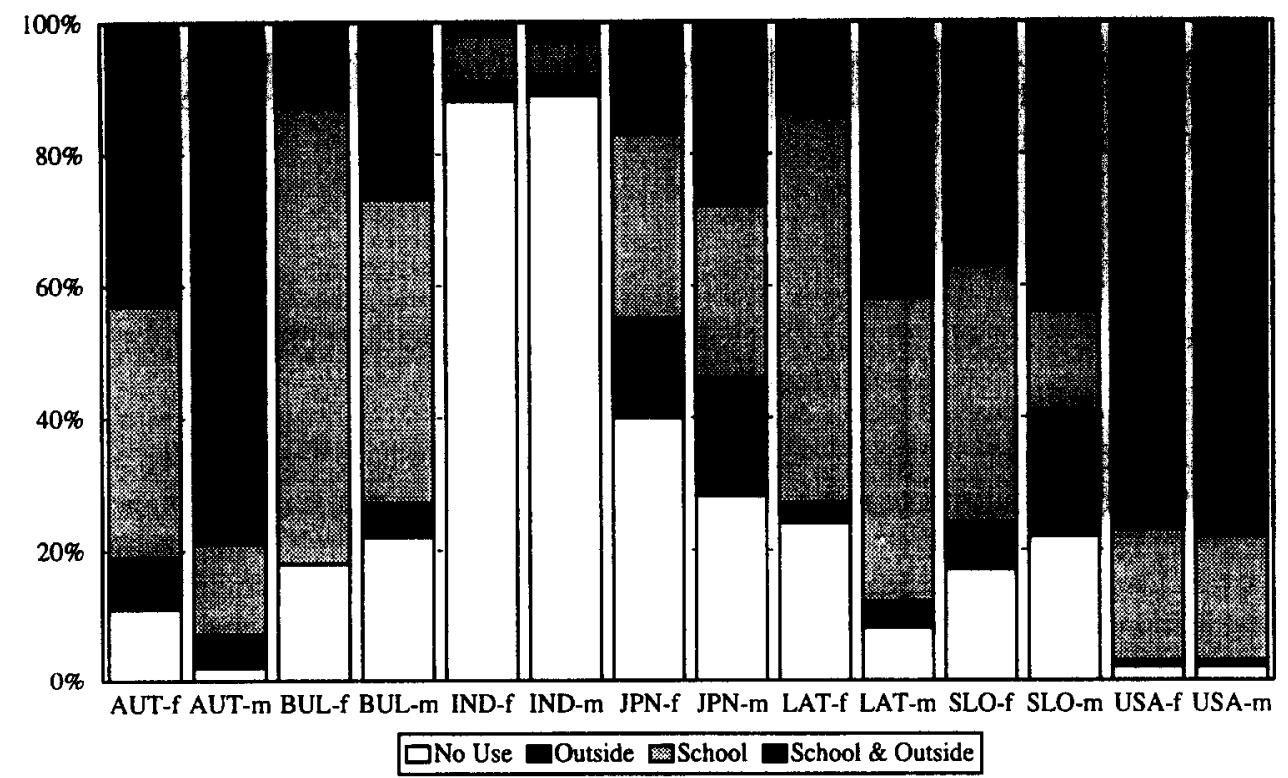

Fig. 5. Percent females ( $f$ ) and males $(m)$ belonging to each of the four user groups. $M=$ information not available or too many missing cases ( $>20 \%$ ).

school (Japan and the Netherlands in lower secondary education and Japan and Slovenia in upper secondary education). An equal number of countries is found in which the boys' score is higher for the group that uses the computer only at school (Austria and U.S.A. in lower secondary education and India and U.S.A. in upper secondary education). The above results indicate that in many countries, the school is an important environment for female students to work with computers in the sense that it compensates for the lack of opportunity to work with computers outside school. From an equity perspective, this is an important argument for stimulation policies in the area.

The fact that there are differences in access to computers, might also be an indication of the difference in attitudes towards computers as mentioned before. Analysing the results on the relevance scale for both males and female of the four types of computer using groups (no use, only outside, only at school or both outside and inside school), a noteworthy difference appears between the group of females "outside school" and "inside school". In most countries, across all three populations, females agree more on the relevance of computer use when they use the computer at school. If one can assume that relevance of working with computer is a prerequisite for optimal computer use, then again the conclusion is that the school environment and the possibilities of using computers in the school is especially important for female students.

Concerning the enjoyment-scale, we found that girls score higher on the enjoyment scale when using the computer at school in the U.S.A. (lower secondary education) and Austria (upper secondary education). The most striking observation is the great difference in enjoyment of boys when comparing the group of outside school users and inside school users. In Germany, Japan and the Netherlands in lower secondary education and in Japan in upper secondary education, the scores on the enjoyment scale are considerably lower for the group of males who only use the computer at school. The difference in percentage agreement range from $10 \%$ (Germany and Japan in lower secondary education) to $23 \%$ in Japan in upper secondary education. The Comped data show also [10] that the group of "only outside school" computer users is more motivated to use computers; the findings presented above seem to indicate that this particularly holds for male students.

To summarize, the findings in this section concerning the "input" variables in the gender debate seem to indicate that the "input" for computer use by females is different than for males: indications are found that socialization experiences and access to computers lead, at least in some countries, to the creation and/ or preservation of gender differences. As we found that gender equity is least a problem in the U.S.A., 
in this section is was found that parental support is high (and equally given to both sexes) in this country, and female and male students are the most "equal" in terms of using the computer both inside and outside the school. Unfortunately, the same conclusion cannot be drawn for Bulgaria, the other country which we found to be rather "gender-equal" in terms of computer use. Gender equity is a major problem in Austria, Germany and Latvia, and we found in this section that a large difference between the gender groups in access to computers, both in terms of availability and use, might be one of the factors explaining this difference.

\section{PROCESS VARIABLES: THE ROLE OF THE SCHOOL WITH RESPECT TO GENDER DIFFERENCES}

An important conclusion of the previous section is that the school seems to be an important environment for female students to work with computers in the sense that it might compensate for the lack of opportunity to work with computers outside school. For this reason it is relevant to investigate to what extent gender differences appear in the school environment. Factors mentioned in the literature concerning influences of the school deal, among others, with the role of the teacher, the type of activities carried out with the computer, and the policy of the school with regard to the gender issue.

\section{Teacher role model}

It is generally accepted that it is important that girls get examples of women working with the computer, serving as a role model for them. This can be realized in various ways, one being the role models provided by the staff of the school.

When looking at the number of female staff positions (principals, computer coordinators and teachers, see Fig. 6) in the computer using schools, it is found that in most countries (except Bulgaria, Latvia and the U.S.A.) the majority of staff positions are occupied by males.

The finding of a more positive situation in female staff positions in Bulgaria and the U.S.A. might be one of the factors contributing to the earlier conclusion of these countries being the most "gender equal".

Although in some countries the situation of female computer coordinators and teachers positively changed in the period between 1989 and 1992, the overall picture in 1992 shows that computer use is still a male dominated activity. The large decrease in female principals in Greece was discussed with the national center of the study but no explanation could be found yet for this finding.

Due to the small numbers in the sample, no further analyses were possible on the type of role model female or male teachers provide their students with. In order to get an impression about the type of role model of teachers, we summarize the findings of Comped data from 1989 [15]. These data showed that female teachers give themselves a lower self-rating with regard to computer knowledge and skills as compared to their male colleagues. The largest differences were observed regarding the self-ratings about programming. Concerning the attitude of teachers towards computers, it was found that male teachers have significantly greater self-confidence regarding computers. These findings suggests that the type of role model female teachers provide is qualitatively different from the one male teachers provide.

\section{Type of computer use}

When considering the use of the computer at school, one question is whether female students, when they have access to computers at school, indicate doing the same activities (regardless of the intensity of doing these activities). Figure 7 shows the results for this question.

It is clear that, on average, male students are engaged in a greater number of activities than females. Especially in Austria, India and Latvia in upper secondary education, these differences are notably large. Only in Slovenia in upper secondary education, female students indicate doing somewhat more activities with computers than males.

An inspection of the different types of activities for which the computer is used shows that in most countries males indicate on all activities a slightly higher percentage of being engaged in it. Only 
Germany and Greece in lower secondary education and Japan and Slovenia in upper secondary education are the countries in which females indicate relatively more use on many activities. Female students indicate a higher engagement in word processing especially in Japan, but also in Slovenia (upper secondary education).

Thus, a first conclusion is that female students, when having access to computers at school, are engaged in less activities than males. As an earlier conclusion was that computer use at school is especially important for female students in order to compensate for lack of outside school access, this new result might, to some extent, be alarming because it indicates again a gender inequity, this time

\section{Percent Female Principals}

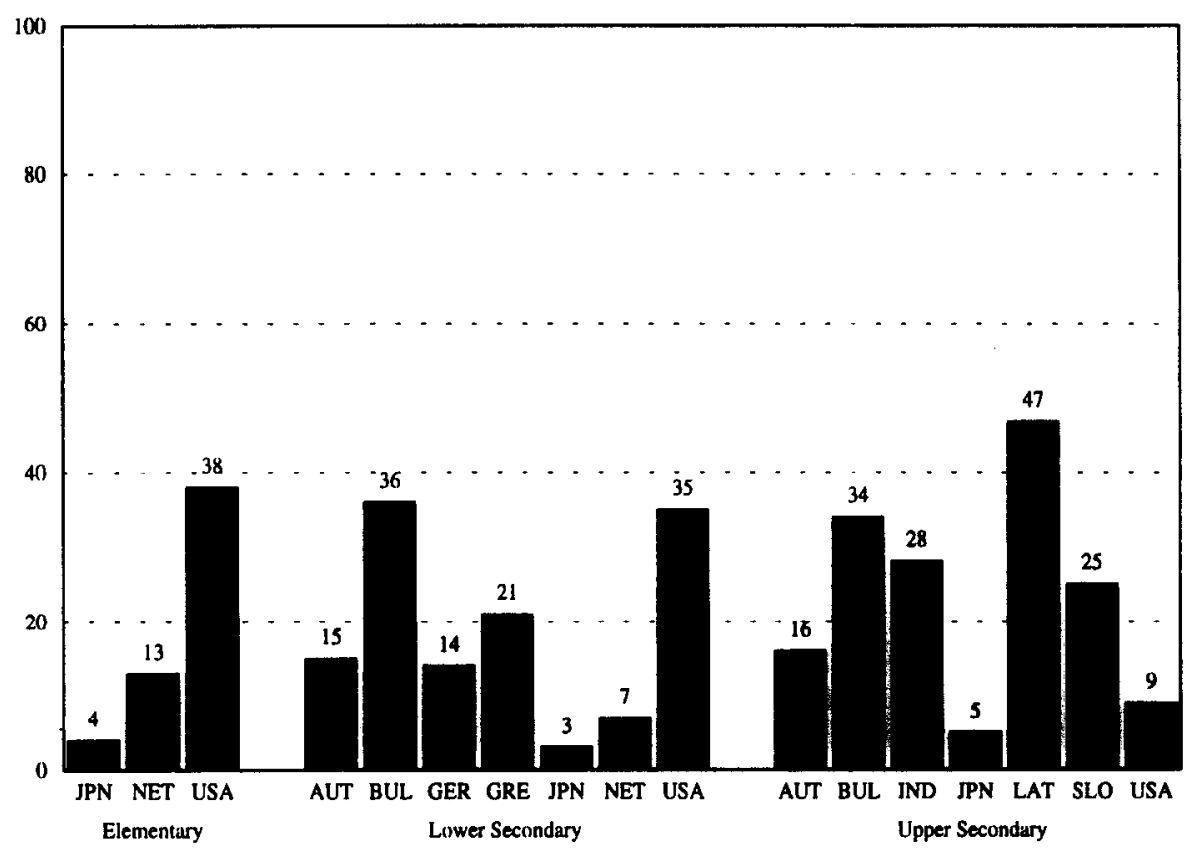

Percent Female Computer Coordinators

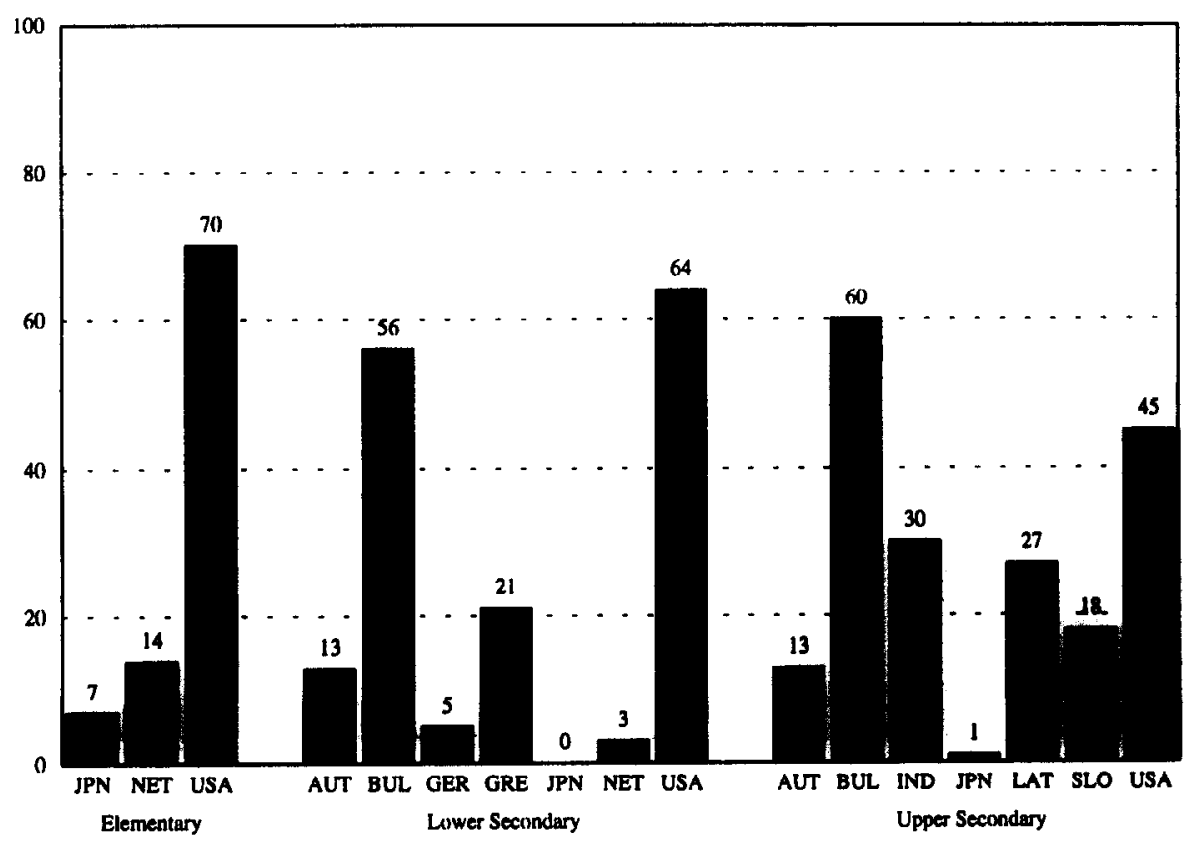

Fig. 6. Continued overleaf. 


\section{Percent Female Teachers}

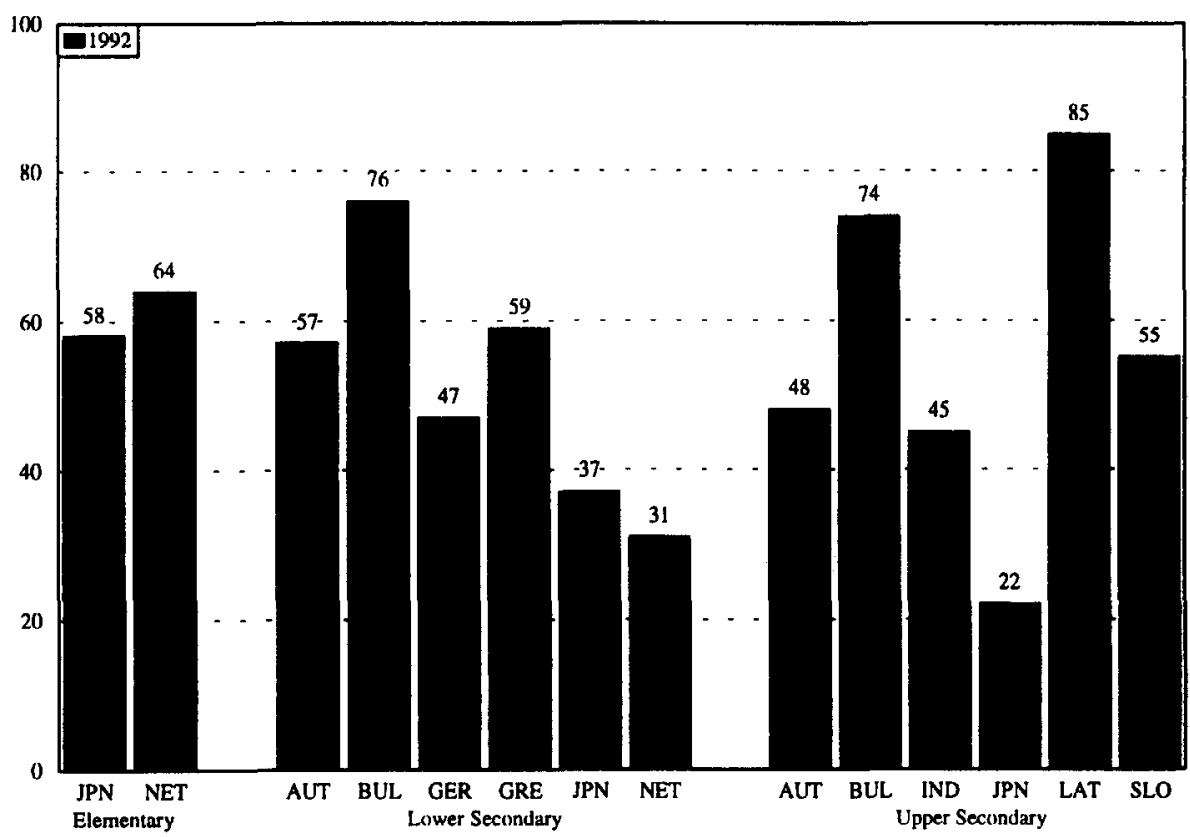

Fig. 6. Percent female principals, computer coordinators and teachers in computer using schools.

inside the school environment. However, further analyses are needed before more firm conclusions can be drawn.

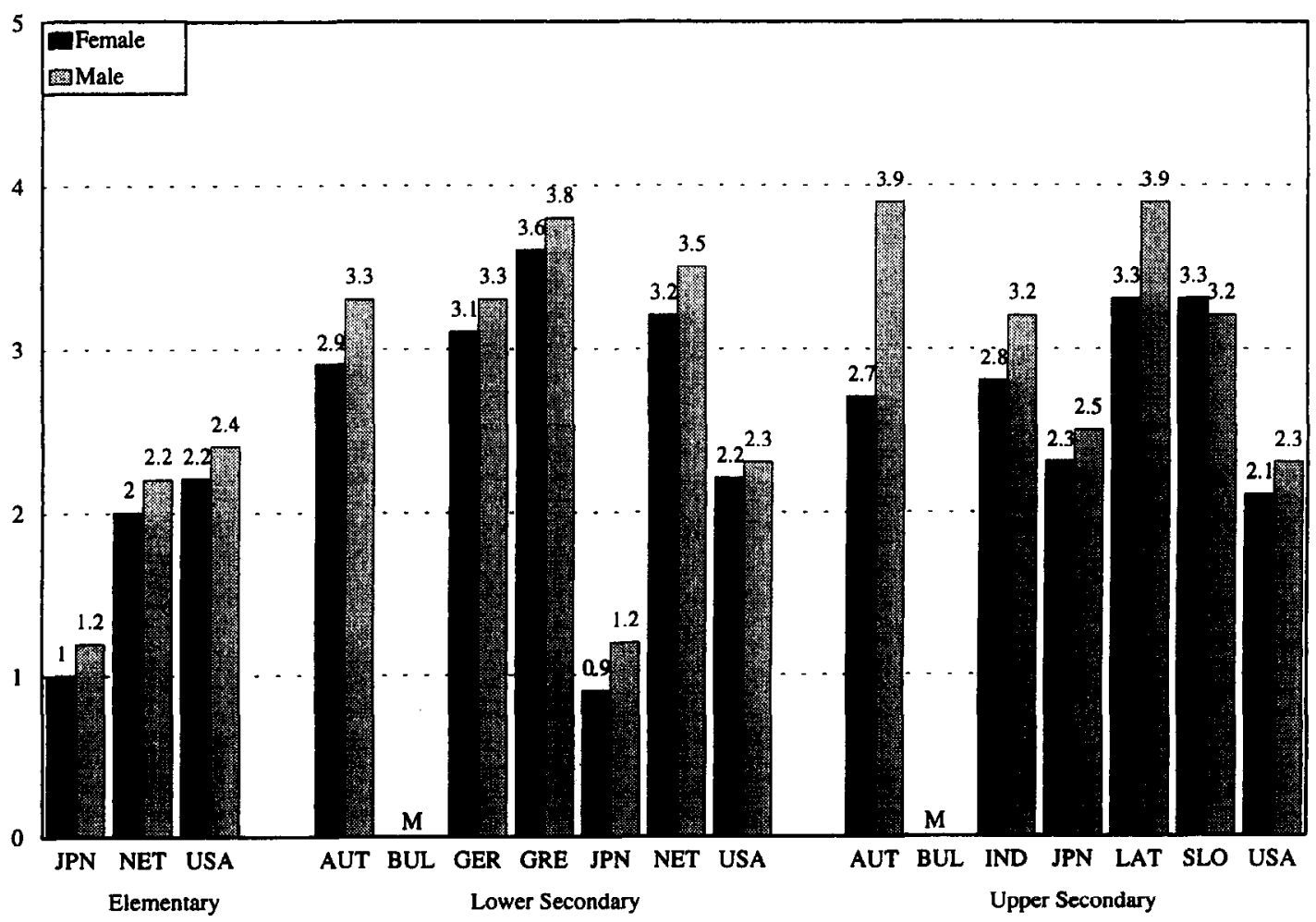

Fig. 7. Mean number of activities carried out with the computer for female and male students who work with the computer at school or both at school and outside school. 


\section{School gender policy}

From the Comped data, it can be concluded [7] that school gender policies with respect to computers in education is not an important topic in the schools of the countries participating in this study. In most countries, only a small minority of schools have a special policy to promote gender equity in the area of computer use. In case schools do have a special gender policy, it is directed towards training female teachers in computer education, giving teachers suggestions on how to promote equity, or in-service sessions for teachers about equity.

\section{SUMMARY AND CONCLUSION}

The findings of the Comped data are indicating that the concerns of many educational practitioners about gender equity is well founded. At the output level, results indicate that females know less about information technology, enjoy using the computer less than male students, and perceive more software problems. A multi-level analyses on the Comped data done by ten Brummelhuis [16] shows that the gender of students is a factor with a substantial influence on student achievement in the countries.

Possible causes of these differences as identified in this paper deal with differences in parental support, access to computers (in terms of availability and use), amount of female role models and activities carried out with the computer at school. Attitudes towards IT and home background are also found in the ML analyses to be meaningful factors in understanding differences in student achievement.

But do the Comped data also provide some clues for possible ways to improve this situation? The first step might be to recognize that gender differences are found both outside and inside school. This mcans that both parents and teachers have to be made aware of this situation as the basis for action in reducing the difference. As indicated in the section above, a school's policy concerning the gender issue is rare, and when a school has such a policy, it is not directed towards the parents. Concerning the teachers, the perspective chosen by a majority of schools seems to be the stimulation of female role models, but making both female and male teachers aware of the gender difference between male and female students is done as well.

The analyses on the Comped data seem to indicate that differences in FITT scores between female and male students are found for all countries included in the study except the U.S.A. and Bulgaria, all indicating that females score lower on the test. Factors that might contribute to this "gender equal" situation in Bulgaria and the U.S.A. might be the availability of female staff positions at school (especially in Bulgaria were the use of the computer outside school is very limited) and in the U.S.A. the equality of the home situation (parents stimulation and availability/use of computers outside school). In the more "gender unequal" countries like Austria, Germany, Japan, Latvia and Slovenia the situation of working with computers outside school is at least less favourable for females. However, it is too early to state that these differences are fixed. As found in the Comped study, computer use in the schools is in many countries still quite limited and developments are expected in the coming years. In that respect it is important that all people involved in this process of implementing the computer, constantly keep in mind that this new technology should not broaden the gap between possibilities for female and male students.

\section{REFERENCES}

1. Damarin, S. K., Rethinking equity: an imperative for educational computing. The Computing Teacher, 1989, 16(7), 16-18.

2. Durndell, A., Macload, H. and Siann, G., A survey of attitudes, knowledge about and experience of computers. Computers in Education, 1987, 11(3), 167-175.

3. Shashaani, L., Socio economic status, parents' sex-role stereotypes, and the gender gap in computing. Joumal of Research on Computing in Education, 1994, 26(3), 433-451.

4. Voogt, J., Vrouwen en informatica: meisjes in het ISI-project [Women and Informatics: girls in the ISI-project]. PCBB, 's-Hertogenbosch, The Netherlands, 1987.

5. Janssen Reinen, I. A. M. and Plomp, Tj., Gender and new technology. In International Encyclopedia on Education, 2nd edn, eds T. Husén and T. N. Postlethwaite. Pergamon Press, Oxford, 1994, pp. 2423-2427.

6. Sutton, R. S., Equity and computers in the schools: a decade of research. Review of Educational Research, 1991, 61(4), 475-503.

7. Janssen Reinen, I. A. M. and Plomp, Tj., Gender and Computers: another area of inequity in education? In Schools, Teachers, Students and Computers: A Cross-National Perspective, eds W. J. Pelgrum, I. A. M. Janssen Reinen and Tj. Plomp. IEA, Amsterdam, 1993.

8. Martin, R., School children's attitudes towards computers as a function of gender, course subjects and availability of home 
computers. Journal of Computer Assisted Learning, 1991, 7, 187-194.

9. Siann, G., Macload, H., Glissov, P. and Durndell, A., The effect of computer use on gender differences in attitudes to computers. Computers in Education, 1990, 14(2), 183-191.

10. Pelgrum, W. J., Janssen Reinen, I. A. M. and Plomp, Tj,, Schools, Teachers, Students and Computers: A Cross-National Perspective. IEA-Comped Study Stage 2. IEA, Amsterdam, 1993.

11. Pelgrum, W. J. and Plomp, Tj., The Use of Computers in Education Worldwide. Pergamon Press, Oxford, 1992.

12. Pelgrum, W. J. and Plomp, Tj., What do students know, learn and think about computers. In Schools, Teachers, Students and Computers: A Cross-National Perspective, eds W. J. Pelgrum, I. A. M. Janssen Reinen and Tj. Plomp. IEA, Amsterdam, 1993.

13. Collis, B., Sex differences in secondary school students' attitudes towards computers. The Computer Teacher, 1985, 4, 33-36.

14. Yeloushan, A., Social barriers hindering successful entry of females into technology-oriented fields. Educational Technology, $1989,29(11), 44-46$.

15. Janssen Reinen, I. A. M. and Plomp, Tj., Some gender issues in educational computer use: results of an international comparative survey. Computers in Education, 1993, 20(4), 353-365.

16. ten Brummelhuis, A. C. A., What do students know about computers and where did they learn it? Results from an international comparative survey. Paper presented at the AREA, New Orleans. University of Twente, Enschede, 1994.

17. Janssen Reinen, I. A. M. and ten Brummelhuis, A.C.A., Informatie technologie en sexespecifieke verschillen: Is er sprake van een ongelijkheid in computergebruik? [Information technology and gender differences: is there inequity in computer use?]. Paper presented at the Educational Research Days 1994, Utrecht, 1994.

\section{APPENDIX A}

Mean percent of female $(f)$ and male $(m)$ students in each country that answered each option of the gender question

\begin{tabular}{|c|c|c|c|c|c|c|c|c|c|c|c|c|}
\hline & \multicolumn{3}{|c|}{ Play gamest } & \multicolumn{3}{|c|}{ Practical Job $†$} & \multicolumn{3}{|c|}{ Comp. program. $\dagger$} & \multicolumn{3}{|c|}{ Knowledge $\dagger$} \\
\hline & Boys & Equal & Girls & Boys & Equal & Girls & Boys & Equal & Girls & Boys & Equal & Girls \\
\hline \multicolumn{13}{|l|}{ Elem. } \\
\hline JPN-f & 72 & 26 & 2 & 23 & 49 & 28 & 42 & 31 & 27 & 49 & 38 & 13 \\
\hline JPN-m & 80 & 18 & 2 & 31 & 50 & 19 & 47 & 33 & 20 & 60 & 31 & 8 \\
\hline NET-f & 33 & 65 & 1 & 26 & 66 & 8 & 34 & 61 & 5 & 28 & 69 & 3 \\
\hline NET-m & 48 & 52 & 0 & 24 & 71 & 6 & 37 & 59 & 4 & 40 & 60 & 1 \\
\hline U.S.A.-f & 16 & 76 & 8 & 11 & 52 & 37 & $\mathbf{M}$ & $\mathbf{M}$ & $\mathbf{M}$ & 12 & 64 & 24 \\
\hline U.S.A.-m & 36 & 60 & 4 & 23 & 53 & 23 & $\mathbf{M}$ & $\mathbf{M}$ & $\mathbf{M}$ & 38 & 55 & 7 \\
\hline \multicolumn{13}{|l|}{ Low. Sec. } \\
\hline AUT-f & 40 & 59 & 1 & 31 & 60 & 9 & 62 & 34 & 4 & 38 & 60 & 2 \\
\hline AUT-m & 53 & 45 & 1 & 37 & 55 & 7 & 61 & 34 & 5 & 49 & 50 & 2 \\
\hline BUL-f & 35 & 62 & 3 & 18 & 69 & 14 & 22 & 60 & 18 & 33 & 60 & 7 \\
\hline BUL-m & 62 & 36 & 2 & 29 & 60 & 11 & 29 & 53 & 18 & 44 & 50 & 6 \\
\hline GER-f & 60 & 40 & 0 & 34 & 55 & 11 & 36 & 56 & 8 & 54 & 46 & 1 \\
\hline GER-m & 72 & 28 & 1 & 38 & 55 & 7 & 40 & 49 & 11 & 58 & 42 & 1 \\
\hline GRE*-f & 36 & 62 & 2 & 21 & 63 & 16 & 21 & 69 & 10 & 32 & 60 & 8 \\
\hline GRE*-m & 70 & 29 & 1 & 35 & 56 & 8 & 36 & 56 & 8 & 58 & 38 & 3 \\
\hline JPN-f & 80 & 19 & 1 & 30 & 51 & 19 & 28 & 40 & 31 & 63 & 31 & 5 \\
\hline JPN-m & 85 & 14 & 1 & 37 & 46 & 17 & 34 & 38 & 28 & 58 & 35 & 8 \\
\hline NET-f & 48 & 51 & 1 & 20 & 71 & 9 & 33 & 63 & 3 & 31 & 67 & 2 \\
\hline NET-m & 56 & 43 & 1 & 16 & 73 & 10 & 33 & 63 & 4 & 35 & 64 & 1 \\
\hline U.S.A.-f & 41 & 56 & 2 & 9 & 58 & 33 & 16 & 57 & 27 & 12 & 73 & 15 \\
\hline U.S.A.-m & 57 & 40 & 3 & 15 & 63 & 22 & 23 & 56 & 21 & 28 & 67 & 5 \\
\hline \multicolumn{13}{|l|}{ Upp. Sec. } \\
\hline AUT-f & 56 & 44 & 0 & 26 & 69 & 5 & 73 & 26 & 0 & 45 & 54 & 1 \\
\hline AUT-m & 60 & 39 & 0 & 35 & 63 & 3 & 67 & 33 & 0 & 58 & 42 & 0 \\
\hline BUL-f & 46 & 51 & 3 & 20 & 69 & 10 & 29 & 57 & 14 & 41 & 54 & 5 \\
\hline BUL-m & 65 & 33 & 2 & 39 & 55 & 6 & 36 & 50 & 15 & 56 & 41 & 3 \\
\hline IND-f & 17 & 74 & 9 & 15 & 62 & 23 & 15 & 61 & 24 & 21 & 68 & 11 \\
\hline IND-m & 30 & 65 & 4 & 28 & 62 & 10 & 28 & 55 & 16 & 35 & 59 & 6 \\
\hline JPN-f & 86 & 13 & 1 & 32 & 48 & 20 & 31 & 39 & 29 & 60 & 35 & 4 \\
\hline JPN-m & 87 & 12 & 1 & 38 & 47 & 15 & 40 & 38 & 22 & 59 & 38 & 4 \\
\hline LAT-f & 57 & 42 & 2 & 48 & 48 & 4 & 64 & 33 & 3 & 76 & 21 & 3 \\
\hline LAT-m & 71 & 27 & 1 & 59 & 37 & 4 & 68 & 28 & 4 & 78 & 20 & 2 \\
\hline SLO-f & 60 & 39 & 1 & 53 & 42 & 4 & 33 & 62 & 5 & 45 & 50 & 4 \\
\hline SLO-m & 74 & 25 & 1 & 60 & 38 & 2 & 31 & 60 & 10 & 56 & 43 & 1 \\
\hline U.S.A.-f & 68 & 31 & 1 & 9 & 66 & 24 & 21 & 59 & 19 & 15 & 77 & 8 \\
\hline U.S.A.-m & 76 & 23 & 1 & 15 & 67 & 18 & 29 & 53 & 18 & 36 & 60 & 4 \\
\hline
\end{tabular}

Notes: $M=$ information not available or too many missing cases ( $>20 \%$ ).

*Only students in computer using schools.

$\dagger$ See Table 2 for full text. 